\title{
Dendritic Cells in Human Renal Inflammation - Part II
}

\author{
Elfriede Noessner $^{a} \quad$ Maja Lindenmeyer ${ }^{c}$ Peter J. Nelson ${ }^{b}$ Stephan Segerer ${ }^{c} d$ \\ a Institute of Molecular Immunology, Helmholtz Zentrum München, German Research Center for Environmental \\ Health, and ${ }^{b}$ Medizinische Poliklinik-Innenstadt, University of Munich, Munich, Germany; ${ }^{~}$ Division of Nephrology, \\ University Hospital Zurich, and ${ }^{\mathrm{d}}$ Institute of Anatomy, University of Zurich, Zurich, Switzerland
}

\section{Key Words}

Dendritic cells $\cdot$ Glomerulonephritis $\cdot$ Interstitial inflammation

\begin{abstract}
Dendritic cells (DCs) are bone marrow-derived professional antigen-presenting cells that act as master regulators of acquired and innate immune responses. Here, we review the available information on their role in human renal inflammation. In the 1980s and early 1990s, major histocompatibility complex class II antigen- (HLA-DR) positive DCs were first described in normal human kidneys and in the interstitium of kidneys from patients with glomerulonephritis. Several DC subtypes were subsequently distinguished based on their expression of CD1C/BDCA-1, CD141/BDCA-3 and CD209/ DC-SIGN (in combination with HLA-DR). These cells were almost exclusively found in the tubulointerstitium, with increased numbers seen during glomerulonephritis. It appears that the human renal tubulointerstitium harbors different DC types which allow the collection of both exogenous as well as endogenous antigens. Plasmacytoid DCs have a plasma cell-like morphology and were commonly found within nodular tubulointerstitial infiltrates. Follicular DCs are rarely seen, but show a predominant localization in organized infiltrates. CD207/langerin is a marker for Langerhans cells. Langerin-positive cells have been found in asso-
\end{abstract}

ciation with the collecting ducts and urothelium. A functional characterization of these subtypes has been hampered by the difficulty of obtaining samples for analysis. However, these studies are clearly required to define the role of DCs and DC subsets in the pathophysiology of renal disease.

Copyright $\odot 2011$ S. Karger AG, Basel

\section{Introduction}

Dendritic cells (DCs) are a potent class of antigen-presenting cells that control the initiation and progression of immune responses $[1,2]$. They play an important role in moderating the balance between tolerance and immunity $[3,4]$. The general biology of DCs and their subsets and the role of DCs in experimental renal inflammation are discussed by Lindenmeyer et al. [5] in this issue. Here, we focus on the current status of DC biology in human renal disease.

\section{Human DC Subsets}

Due to the lack of a specific marker, the definition of DCs and their distinction from monocyte/macrophages is difficult in humans. In the mouse, CD11c is an acceptable marker for the identification of DCs. However, in

\section{KARGER \\ Fax +41613061234 \\ E-Mail karger@karger.ch}

www.karger.com

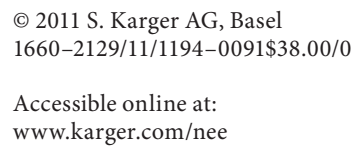

Stephan Segerer, MD

Division of Nephrology, University Hospital Zurich

Rämistrasse 100

$\mathrm{CH}-8091$ Zurich (Switzerland)

Tel. +41 4425596 98, E-Mail Stephan.segerer@usz.ch 
humans, CD11c is also expressed by nearly all monocytes and macrophages. Moreover, the observation that monocytes can readily differentiate into DCs in vitro and in vivo and that DCs from the peripheral blood can also differentiate into macrophages supports the contention that the macrophage/DC association is a continuum rather than a collection of defined cell types [6-9]. The different types of human DCs as defined by their most common markers and proposed functions are illustrated in table 1 and figure 1 . As more is learned about these cells, the collection of DC subtypes and their markers will likely be expanded in the near future.

DC subsets in humans have been readily characterized in the blood using the markers CD1c/BDCA-1, CD303/ BDCA-2, CD141/BDCA-3 and CD204/BDCA-4 [10, 11]. These markers are not expressed in the same way in mice, which complicates a direct comparison of DC subsets between mouse and man.

Human plasmacytoid DCs (pDCs) are distinguished from myeloid DCs by their expression of CD303/BDCA-2 and CD304/BDCA-4, and the absence of the common myeloid markers CD68, CD13 and CD33. Myeloid DCs are CD13 and CD33 positive, and can be further subdivided into conventional (monocyte-independent) DCs (cDCs) and monocyte-derived DCs (mo-DCs). In the mouse, the expression of CD8 $\alpha$ distinguishes two groups of cDCs with important effector subtypes [reviewed in 5]. Although CD8 $\alpha$ is not expressed on human myeloid cells, they are thought to be functionally similar $\mathrm{CDCs}$ that can be distinguished by a mutually exclusive expression of CD1c/BDCA-1 and CD141/BDCA-3. The CD141/BDCA3-positive myeloid DCs are the less frequent subset that are functionally characterized by a high capacity to crosspresent antigen to CD8-positive $\mathrm{T}$ cells, suggesting that they are functional orthologs to the mouse CD8+ DC subset [12-16]. Human CD141/BDCA-3 positive DCs express the chemokine receptor XCR1 [15], CD205/DEC205 (important for antigen uptake, trafficking and presentation), and the C-type lectin Clec9A (a receptor for necrotic cells) as in murine CD8-positive DCs [17]. These molecules are thought to be associated with the enhanced capacity of this DC subset to cross-present antigen.

Follicular DCs (FDCs) are a specialized subset of DCs. They are not derived from the hematopoietic lineage and are found in the $\mathrm{B}$ cell zone of secondary lymphoid tissues [18]. FDCs can restimulate both B cells and T cells and appear to help maintain immune memory in tandem with B cells. They do not express common myeloid or lymphoid markers and are positive for CD21.

\section{DCs in Non-Lymphoid Peripheral Tissues}

The complexity of DC subsets increases as the cells undergo phenotypic and functional adaptations in response to local tissue-specific microenvironments. The biology of DCs in non-lymphoid peripheral tissues is at present not well understood. Most studies of tissue DCs have been performed in mouse models, and for many defined murine subsets the human counterparts remain to be identified [7, 19]. Both in mouse and in human, the best characterized organ with regards to the DC biology is the skin. It harbors the characteristic Langerhans cells which were the first DCs recognized as a distinct cell subset by the presence of Birbeck's granules, now known as CD207/langerin (fig. 1). Other peripheral organs with well-studied DC biology include the gut and lung [reviewed in 19]. The recognition of resident DCs in the human kidney occurred much later, in part due to the difficulty in tissue availability.

In the peripheral organs, DC subpopulations are thought to be largely derived from monocytes which infiltrate the tissue and become polarized by the specific tissue microenvironment [6]. As in the lymphoid tissues, peripheral organs contain at least two monocyte-derived myeloid subsets of DCs (mo-DCs). These are distinguished by the mutually exclusive presence of the marker CD103 or the chemokine receptor $\mathrm{CX}_{3} \mathrm{CR} 1$. These subsets are thought to exert different functions with the CD103-positive DCs (i.e. the less frequent subset) being largely responsible for generating CTL immunity and tolerance to tissue-associated pathogens and antigens. The poorly migratory $\mathrm{CX}_{3} \mathrm{CR} 1$-positive $\mathrm{DC}$ subset is thought to help activate tissue-infiltrating effector or memory T cells $[19,20]$.

\section{DCs in the Human Kidney}

Functional studies of DCs in human kidney, particularly in the context of intrinsic renal diseases are limited and difficult to perform [21-23]. Very little data are available from studies where these cell types have been extracted from human renal tissues. Therefore, at present the combination of markers provides only a suggestion as to the potential functional roles of these cells in the kidney.

The first description of major histocompatibility complex (MHC) class I [human leukocyte antigen (HLA)$\mathrm{ABC}]$ and MHC class II- (HLA-DR) positive cells in the human tubulointerstitium was published in 1981 [24]. In this study, HLA-DR and HLA-ABC were detected in four kidneys not suitable for transplantation [24]. These anti- 


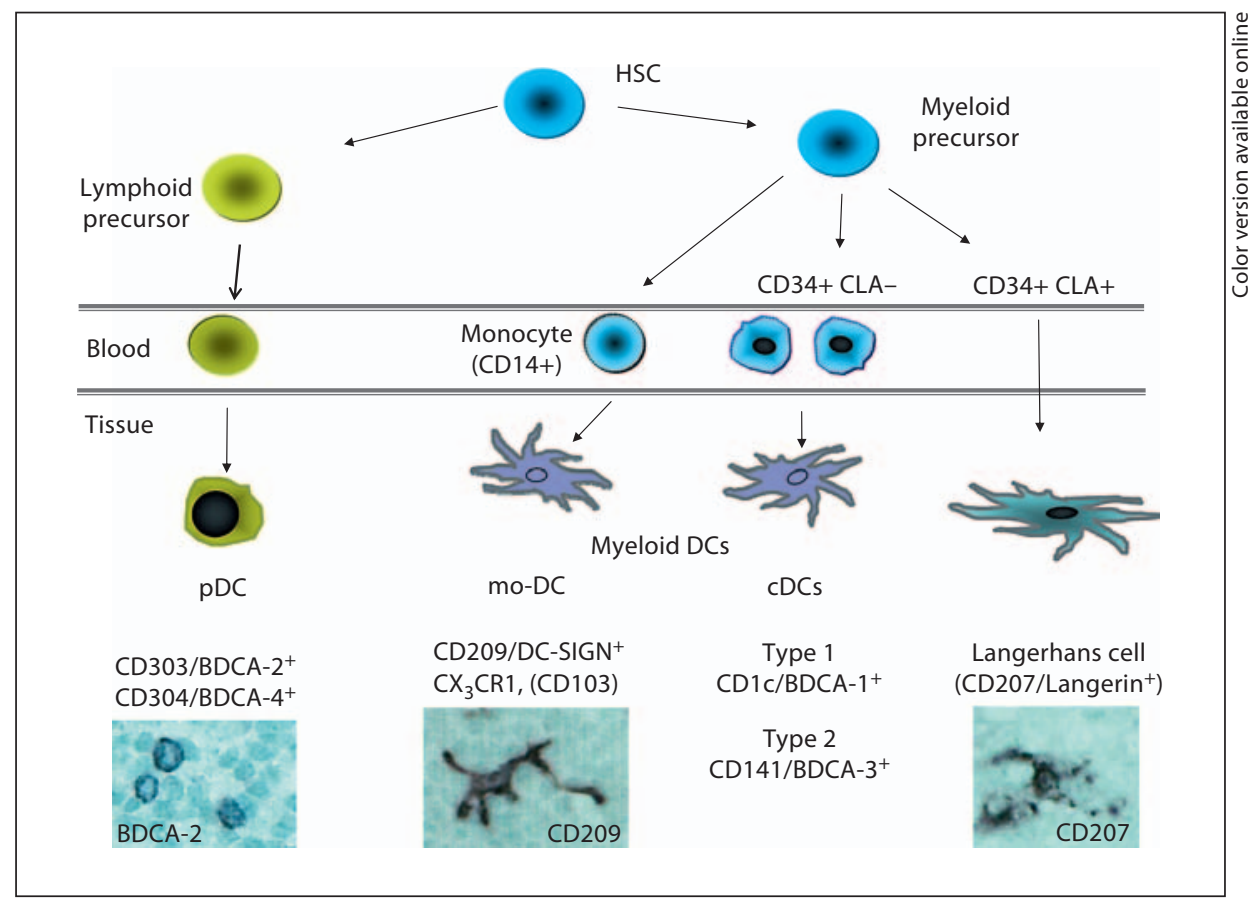

Fig. 1. DC development and DC subsets. This rough overview depicts DC development and subset specification. DCs derive from hematopoietic precursors (HSC) and develop along two branches: the lymphoid branch gives rise to the plasmacytoid CD303/BDCA-2- and CD304/BDCA-4-positive DCs (pDCs). The myeloid branch gives rise to the tissue Langerhans cells (CD207/langerin+), as well as the blood-resident monocytes and conventional myeloid DCs (CD1c/BDCA-1 positive, or CD141/ BDCA-3 positive). Recruited to peripheral tissues, DCs further diversify and may express a variety of markers including CD103 and CD209/DC-SIGN. Thereby, the cDCs are further divided into the so-called type 1 and type $2 \mathrm{cDCs}$. Immunohistochemistry pictures illustrate the 'lymphocytic' morphology of CD303/ BDCA-2-positive cells, the stellate appearance of myeloid CD209positive DCs and the CD207-positive Langerhans cells. Immunohistochemistry illustrates BCDA-2-positive pDCs in a biopsy with lupus nephritis (left); CD207 and CD209 are pictures from human tonsils.

Table 1. Human DC subsets, phenotypic markers and functional characteristics

\begin{tabular}{|c|c|c|}
\hline DC subset & Phenotypic markers & Proposed function \\
\hline $\begin{array}{l}\text { Langerhans } \\
\text { cell }\end{array}$ & $\begin{array}{l}\text { myeloid marker positive }[\mathrm{CD} 13+, \mathrm{CD} 33+] \\
\text { CD207/langerin }+, \mathrm{CD} 1 \mathrm{a}+, \mathrm{CD} 2+, \mathrm{CD} 45 \mathrm{RO}+\end{array}$ & $\begin{array}{l}\text { first immunologic barrier to the external } \\
\text { environment }\end{array}$ \\
\hline $\mathrm{pDC}$ & $\begin{array}{l}\text { myeloid marker negative [CD13-, CD33-], CD303/BDCA-2+, CD304/ } \\
\text { BDCA-4+, CD2-, CD4+, CD45RA+, CD1c/BDCA-1-, CD141/BDCA-3- }\end{array}$ & $\begin{array}{l}\text { high production of type I interferons } \\
(\text { IFN } \alpha / \beta) \text {, antiviral response }\end{array}$ \\
\hline Myeloid DC & myeloid marker positive $\left[\mathrm{CD} 13+, \mathrm{CD} 33+, \mathrm{CD} 11 \mathrm{c}^{\mathrm{dim}}\right], \mathrm{CD} 4+, \mathrm{CD} 45 \mathrm{RO}+$ & \\
\hline cDC type 1 & $\begin{array}{l}\text { CD1c/BDCA-1+, CD2+, CD303/BDCA-2-, CD141-, } \\
\text { (CD209/DC-SIGN), (CD14), (CD68), (CD103) }\end{array}$ & $\mathrm{CD} 4 \mathrm{~T}$ cell priming \\
\hline cDC type 2 & $\begin{array}{l}\text { CD141/BDCA-3+, CD2-, CD303-, CD1c-XCR1+, CD205/DEC205+, } \\
\text { Clec9A+ }\end{array}$ & $\begin{array}{l}\text { cross-presentation } \rightarrow \text { CD } 8 \text { T cell response } \\
\text { production of TGF- } \beta \rightarrow \text { tolerance }\end{array}$ \\
\hline mo-DC & CD209/DC-SIGN+, (CX 3 CR1), (CD14), (CD68), (CD103) & inflammation, tissue repair, homeostasis \\
\hline \multicolumn{2}{|c|}{$\begin{array}{l}\text { The list of markers represents a selection that currently best } \\
\text { defines and distinguishes one DC subset from the other subsets. } \\
\text { Markers in bold are characteristic for the indicated DC subset. All } \\
\text { DCs are negative for lineage markers (CD3, CD19, CD20) and } \\
\text { CD56. BDCA-1, -2,-3,-4 stands for blood dendritic cell antigen-1, }\end{array}$} & $\begin{array}{l}\text { narkers were identified to distinguish indi- } \\
\text { human blood. CD209/DC-SIGN is a marker } \\
\text { arkers listed in round brackets may be vari- } \\
\text { yeloid conventional and monocyte-derived } \\
\text { d tissues. }\end{array}$ \\
\hline
\end{tabular}


Fig. 2. CD209/DC-SIGN expression in renal biopsies with lupus nephritis. Illustrated are biopsies with lupus nephritis stained for CD209/DC-SIGN (positive signal in black). Original magnification $\times 200$ (a, b), $\times 400(\mathbf{c})$ and $\times 630$ (d). a A scattered population of CD209/DC-SIGN-positive cells within the well-preserved tubulointerstitium (arrow). b A very prominent accumulation of CD209/DC-SIGN-positive DCs. c The glomerular tufts do not contain CD209/DC-SIGN-positive cells, but a prominent periglomerular accumulation is present (arrow). d At a higher magnification, these cells demonstrate the typical morphology of DCs (arrow).

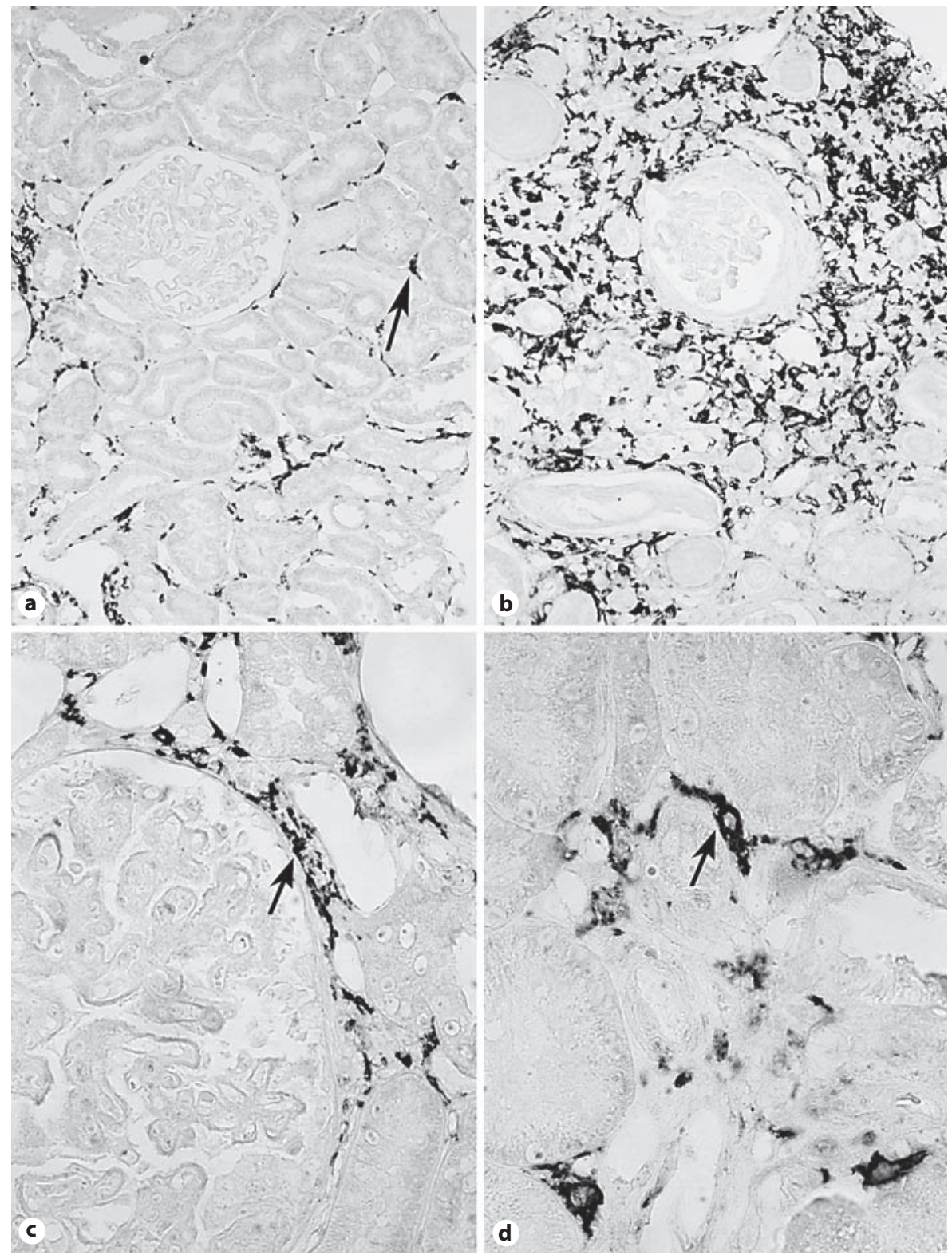

gens were found to be present on endothelium of glomerular and peritubular capillaries. Additionally, cells in the tubulointerstitial space with a dendritic appearance were described to be positive [24]. This important early step in the identification of renal DCs in human renal tissue was followed almost 10 years later by indirect evidence on DCs in inflamed kidneys [25]. In a study on 69 patients with various forms of glomerulonephritis, cell lineage markers (for T cells, B cells, etc.) in addition to MHC antigens HLA-DQ, DR and DP were localized and quantified. The number of HLA-DQ-positive cells outnum- bered the sum of CD14- and CD20-positive cells. The authors concluded that this may indicate that DCs accumulate in the tubulointerstitium during glomerulonephritis in the human kidney [25]. Later, DCs were described in the tubulointerstitium, and were positive for MHC class I (HLA-ABC) as well as MHC class II antigens (HLA-DR, DP and DQ) [26]. The same group provided the first detailed description of these cells in human biopsy material from patients with glomerulonephritis in 1992 [27]. HLA-DR and CD1b were localized in a total of 45 renal biopsies. In the controls, and in biopsies from 
patients with glomerulonephritis but with well-preserved tubulointerstitium, no CD1b-positive cells were found [27]. In contrast, in biopsies with active tubulointerstitial inflammation, CD1b-positive cells were found to be present at sites of inflammatory cell accumulations. Even in this early study, the localization of DCs around injured glomeruli was strongly suggested. The periglomerular accumulation of DCs in human glomerulonephritis reflects the situation described in the mouse; however, the dense network of DCs demonstrated in the mouse was not as prominent in the human kidney $[27,28]$.

Woltman et al. [21] published the first study using more recent markers (table 1) in a detailed analysis of frozen tissues from pre-transplant biopsies $(n=21)$, IgA nephropathy $(n=6)$ and renal allograft rejection $(n=6)$. This important paper described specific aspects of human renal DCs. Using the marker CD209/DC-SIGN, a population of tubulointerstitial cells with dendritic appearance was detected. The majority of these cells were also positive for the MHC class II antigen HLA-DR. Double labeling with CD68 (previously used as a marker for macrophages) revealed colocalization with CD209/DCSIGN in the tubulointerstitium. Using double labeling for CD209/DC-SIGN and CD1c/BDCA-1, it was demonstrated that the majority of CD209/DC-SIGN-positive cells coexpressed CD1c/BDCA-1, but there was also a prominent CD1c/BDCA-1 single positive cell population suggesting a heterogeneous population of DCs in the tubulointerstitium. Based on the current nomenclature, the DC subsets likely correspond to the mo-DCs (which should be the larger proportion) and the type 1 conventional cDCs (which should account for the smaller percentage). Expression of $\mathrm{CX}_{3} \mathrm{CR} 1$ has been described to overlap with the pattern of CD68-positive cells in human renal inflammation, most likely corresponding in part to the mo-DCs [29].

CD303/BDCA-2 positive cells, morphologically reflecting pDCs, were also identified [21]. In the small number of biopsies examined from patients with IgA nephropathy and acute allograft rejection, the number of cells for all three markers was found to be increased, suggesting an accumulation of DCs in the context of inflammation. In normal kidneys, no CD208/DC-LAMP-positive cells were found, indicating the absence of mature DCs in well-preserved renal tissue [21].

We used a similar set of markers in a series of patients with various glomerular diseases [22]. These included 55 biopsies from patients with necrotizing glomerulonephritis, lupus nephritis, focal segmental glomerulosclerosis, membranous nephropathy and minimal change disease. These samples were compared with biopsies without significant renal lesions. In diseases such as proliferative lupus nephritis and necrotizing forms of glomerulonephritis, CD68-positive cells were found to accumulate in the tubulointerstitium and glomeruli. The pattern of the interstitial CD68-positive cells corresponded to the general distribution of CD209/DC-SIGN-positive cells (fig. 2). Using double labeling in combination with confocal microscopy, it was confirmed that these cells were positive for both markers [22]. In contrast, the CD68-positive cells that accumulated in the glomerular tuft did not exhibit CD209/DC-SIGN staining on consecutive sections. Therefore, depending on the tissue compartment examined, the CD68-positive cells appear to represent different subtypes. The glomerular CD68positive cells were negative for CD209/DC-SIGN and appear to be macrophages, whereas in the tubulointerstitium, the majority of CD68-positive cells express CD209/ DC-SIGN and are more likely mo-DCs. The number of CD209/DC-SIGN- and CD303/BDCA-2-positive cells increased in the tubulointerstitium in diseases with progressive interstitial injury and the area of CD209/DCSIGN expression was associated with renal function. CD208/DC-LAMP-positive mature DCs were present in low numbers in the tubulointerstitium of inflamed kidneys, but were very rare in control tissue confirming the results of Woltman et al. [21]. CD207/langerin-positive cells were found in low numbers in the tubulointerstitium, but were common within the epithelium of collecting ducts [22].

Fiore et al. [30] provided data on 21 patients with lupus nephritis and 12 healthy controls. The numbers of CD1C/ BDCA-1-, CD141/BDCA-3- and CD304/BDCA-4-positive cells were found to be significantly increased in the tubulointerstitium in biopsies with lupus classes III and IV. The number of CD208/DC-LAMP-positive mature DCs was again found to be small in this study. The same group recently provided data on 13 patients with lupus nephritis (five classes I-II, five classes III-IV, three class V) [31]. The recruitment of ChemR23-positive pDCs (double labeling for BDCA-2) was demonstrated in the tubulointerstitium from patients with lupus nephritis [31]. ChemR23 is a receptor for chemerin, which could be localized to tubular epithelial cells and lymphatic endothelial cells in biopsies with lupus nephritis [31]. In a transendothelial chemotaxis assay, the recruitment of pDCs by chemerin was demonstrated in vitro [31].

In contrast to the data describing DCs in the tubulointerstitium of mouse and human kidneys, one study found a high number of pDCs in the glomeruli of patients with 
lupus nephritis [32]. These data await further confirmation and have not been supported in two recent studies $[22,30]$.

Castellano et al. [23] demonstrated that CD1c/BDCA1-positive cells in the tubulointerstitium of biopsies with lupus nephritis also express $\mathrm{Clq}$, a protein involved in the initiation of the classical complement pathway. This feature of renal DCs may be related to local complement activation and modulation of the adaptive immune response.

The FDC morphologically represents an additional non-hematopoietic DC type [18]. In renal biopsies from patients with lupus nephritis or vasculitis, organized follicles, so-called tertiary lymphoid organs, develop in a subset of patients [33]. These differentiated lymphoid organs contain CD21-positive FDCs. The functional role of these structures as well as of the CD21-positive FDCs during the disease progress is currently poorly defined.

DCs are also a prominent cell type found within the chronic inflammatory milieu of human renal cell carcinoma (RCC), the most frequent neoplasia of the human kidney. The DCs were found to belong to the $\mathrm{CX}_{3} \mathrm{CR} 1$ CD209 double-positive DC subset, and the majority of these DCs coexpressed macrophage markers (CD163, CD14). With regard to their phenotype, they appear to be similar to DC cell subtypes found in murine kidneys [34] and human inflammatory kidney diseases [22]. As nephrectomy is the treatment of choice for RCCs, tumorand control non-tumor-damaged kidney tissues were available for cell extraction that allowed detailed flow cytometric analysis. This revealed that the CD209/DCSIGN-positive cells exhibit an activated phenotype with high expression of MHC class II antigens (HLA-DR), CD40, CD86 and CD80. Yet, the absence of CD83 and CD208/DC-LAMP suggests that they are not fully matured/licensed DCs. Although more functional studies are clearly warranted, initial studies suggest that these tumor-resident DCs may be involved in stalling an active immune response to the tumor and eliciting a tumorpromoting cytokine and chemokine environment [35].

\section{Where Do We Go from Here?}

It has become clear that prominent numbers of DCs are present in the tubulointerstitium of the normal human kidney and that DCs increase in number during renal injury. At least three DC types can currently be distinguished in the human kidney. The two markers of myeloid DCs, CD209/DC-SIGN and CD1c/BDCA-1, sepa- rate two cell populations, CD209/DC-SIGN and CD1c/ BDCA-1 double-positive and CD209/DC-SIGN-negative CD1c/BDCA-1-positive DCs. Additionally, there are pDCs with a lymphoid morphology expressing CD303/ BDCA-2. Based on their marker combinations, the majority of these cells appear to be immature. Unfortunately, except for our initial studies in RCC, there is at present no experimental information concerning the biologic role of DCs in the human kidney.

A prominent feature of the DC biology in renal tissues is their almost exclusive accumulation in the tubulointerstitium, and not in glomeruli. DCs may be exposed to antigens from different sources. Many small proteins, which reach the tubulointerstitium through regular filtration and reabsorption, should not produce an immune response; rather, they may mediate an active state of tolerance with the help of DCs. In contrast, during ascending infections, and in unselective proteinuria, the DCs become exposed to various proteins not regularly present in the tubulointerstitium. In combination with cytokines and chemokines, this could induce maturation and licensing of the DCs, resulting in rapid exit from the kidney and the potential activation of an acquired immune response in the local lymph nodes. An active propagation of the tubulointerstitial inflammation could help promote an ongoing destruction of this compartment. The role of neolymphangiogenesis seen regularly in inflamed kidneys in the process will need to be studied further [36].

The glomerular tuft is characterized by a low number of DCs and lymphocytes (B cells as well as T cells), while CD68-positive cells without markers of DCs accumulate during glomerulonephritis. These macrophages in combination with activated mesangial cells are involved in the clearance of antigens accumulating in the mesangium. An active acquired immune response could be deleterious in the glomerular tuft where antigens are constantly accumulating and cleared within the mesangial area. Therefore, the presence of DCs in this area may be perilous, while macrophages with their non-immunogenic antigen clearance may represent a more suitable cell type.

The tubulointerstitium may be viewed as the 'alarm system' of the kidney where the right combination of signals is integrated into an acquired immune response, whereas the more delicate glomerulus remains an 'immunoprivileged' microenvironment to support the important functions of size-selective filtration and clearance of mesangial proteins. 
Studies now need to proceed beyond the description of precise marker combinations to the functional description of renal DCs in the human situation. As materials from human kidneys are limited, it seems to be important that the groups in the field combine their future efforts which will help to increase the knowledge in this exciting area of research.

\section{Acknowledgements}

S.S. is supported by a Grant of the University of Zurich, a Clinical Evidence Council grant from Baxter Healthcare Corporation and by the Swiss National Science Foundation (32003B_129710). E.N. is supported by SFB-TR36 and P.J.N. by SFB 571 of the Deutsche Forschungsgemeinschaft.

\section{References}

1 Banchereau J, Palucka AK: Dendritic cells as therapeutic vaccines against cancer. Nat Rev Immunol 2005;5:296-306.

2 Banchereau J, Steinman RM: Dendritic cells and the control of immunity. Nature 1998; 392:245-252.

3 Mahnke K, Schmitt E, Bonifaz L, Enk AH, Jonuleit $\mathrm{H}$ : Immature, but not inactive: the tolerogenic function of immature dendritic cells. Immunol Cell Biol 2002;80:477-483.

-4 Steinman RM, Hawiger D, Nussenzweig MC: Tolerogenic dendritic cells. Annu Rev Immunol 2003;21:685-711.

-5 Lindenmeyer M, Noessner E, Nelson PJ, Segerer S: Dendritic cells in experimental renal inflammation. Nephron Exp Nephrol 2011;119:e83-e90.

-6 Varol C, Landsman L, Fogg DK, Greenshtein L, Gildor B, Margalit R, Kalchenko V, Geissmann F, Jung S: Monocytes give rise to mucosal, but not splenic, conventional dendritic cells. J Exp Med 2007;204:171-180.

-7 Geissmann F, Gordon S, Hume DA, Mowat AM, Randolph GJ: Unravelling mononuclear phagocyte heterogeneity. Nat Rev Immunol 2010;10:453-460.

-8 Randolph GJ, Inaba K, Robbiani DF, Steinman RM, Muller WA: Differentiation of phagocytic monocytes into lymph node dendritic cells in vivo. Immunity 1999;11:753761.

-9 Robinson SP, Patterson S, English N, Davies D, Knight SC, Reid CD: Human peripheral blood contains two distinct lineages of dendritic cells. Eur J Immunol 1999;29:27692778.

10 Ziegler-Heitbrock L, Ancuta P, Crowe S, Dalod M, Grau V, Hart DN, Leenen PJ, Liu YJ, MacPherson G, Randolph GJ, Scherberich J, Schmitz J, Shortman K, Sozzani S, Strobl H, Zembala M, Austyn JM, Lutz MB: Nomenclature of monocytes and dendritic cells in blood. Blood 2010;116:e74-e80.

- 11 Dzionek A, Fuchs A, Schmidt P, Cremer S, Zysk M, Miltenyi S, Buck DW, Schmitz J: BDCA-2, BDCA-3, and BDCA-4: three markers for distinct subsets of dendritic cells in human peripheral blood. J Immunol 2000; 165:6037-6046.
12 Jongbloed SL, Kassianos AJ, McDonald KJ, Clark GJ, Ju X, Angel CE, Chen CJ, Dunbar PR, Wadley RB, Jeet V, Vulink AJ, Hart DN, Radford KJ: Human CD141+ (BDCA-3)+ dendritic cells (DCs) represent a unique myeloid DC subset that cross-presents necrotic cell antigens. J Exp Med 2010;207:12471260 .

13 Robbins SH, Walzer T, Dembele D, Thibault C, Defays A, Bessou G, Xu H, Vivier E, Sellars M, Pierre P, Sharp FR, Chan S, Kastner P, Dalod M: Novel insights into the relationships between dendritic cell subsets in human and mouse revealed by genome-wide expression profiling. Genome Biol 2008; 9:R17.

14 Caminschi I, Proietto AI, Ahmet F, Kitsoulis S, Shin Teh J, Lo JC, Rizzitelli A, Wu L, Vremec D, van Dommelen SL, Campbell IK, Maraskovsky E, Braley H, Davey GM, Mottram P, van de Velde N, Jensen K, Lew AM, Wright MD, Heath WR, Shortman K, Lahoud $\mathrm{MH}$ : The dendritic cell subtype-restricted C-type lectin CLEC9A is a target for vaccine enhancement. Blood 2008;112: 3264-3273.

15 Crozat K, Guiton R, Contreras V, Feuillet V, Dutertre CA, Ventre E, Vu Manh TP, Baranek T, Storset AK, Marvel J, Boudinot $\mathrm{P}$, Hosmalin A, Schwartz-Cornil I, Dalod M: The XC chemokine receptor 1 is a conserved selective marker of mammalian cells homologous to mouse CD8alpha+ dendritic cells. J Exp Med 2010;207:1283-1292.

16 Poulin LF, Salio M, Griessinger E, AnjosAfonso F, Craciun L, Chen JL, Keller AM, Joffre O, Zelenay S, Nye E, Le Moine A, Faure F, Donckier V, Sancho D, Cerundolo V, Bonnet D, Reis e Sousa C: Characterization of human DNGR-1+ BDCA3+ leukocytes as putative equivalents of mouse CD8alpha+ dendritic cells. J Exp Med 2010;207:1261-1271.

17 Contreras V, Urien C, Guiton R, Alexandre Y, Vu Manh TP, Andrieu T, Crozat K, Jouneau L, Bertho N, Epardaud M, Hope J, Savina A, Amigorena S, Bonneau M, Dalod M, Schwartz-Cornil I: Existence of CD8alphalike dendritic cells with a conserved functional specialization and a common molecular signature in distant mammalian species. J Immunol 2010;185:3313-3325.
18 Allen CD, Cyster JG: Follicular dendritic cell networks of primary follicles and germinal centers: Phenotype and function. Semin Immunol 2008;20:14-25.

19 Helft J, Ginhoux F, Bogunovic M, Merad M: Origin and functional heterogeneity of nonlymphoid tissue dendritic cells in mice. Immunol Rev 2010;234:55-75.

20 Bedoui S, Whitney PG, Waithman J, Eidsmo L, Wakim L, Caminschi I, Allan RS, Wojtasiak M, Shortman K, Carbone FR, Brooks AG, Heath WR: Cross-presentation of viral and self antigens by skin-derived CD103+ dendritic cells. Nat Immunol 2009;10:488495.

21 Woltman AM, de Fijter JW, Zuidwijk K, Vlug AG, Bajema IM, van der Kooij SW, van Ham V, van Kooten C: Quantification of dendritic cell subsets in human renal tissue under normal and pathological conditions. Kidney Int 2007;71:1001-1008.

-22 Segerer S, Heller F, Lindenmeyer MT, Schmid H, Cohen CD, Draganovici D, Mandelbaum J, Nelson PJ, Grone HJ, Grone EF, Figel AM, Nossner E, Schlondorff D: Compartment specific expression of dendritic cell markers in human glomerulonephritis. Kidney Int 2008;74:37-46.

23 Castellano G, Trouw LA, Fiore N, Daha MR, Schena FP, van Kooten C: Infiltrating dendritic cells contribute to local synthesis of $\mathrm{Clq}$ in murine and human lupus nephritis. Mol Immunol 2010;47:2129-2137.

-24 Hart DN, Fuggle SV, Williams KA, Fabre JW, Ting A, Morris PJ: Localization of HLA-ABC and DR antigens in human kidney. Transplantation 1981;31:428-433.

25 Markovic-Lipkovski J, Muller CA, Risler T, Bohle A, Muller GA: Association of glomerular and interstitial mononuclear leukocytes with different forms of glomerulonephritis. Nephrol Dial Transplant 1990;5:10-17.

26 Eberlein-Gonska M, Sill H, Waldherr R: Expression of class I and class II histocompatibility antigens in inflammatory kidney diseases (in German). Verh Dtsch Ges Pathol 1989;73:117-123.

27 Cuzic S, Ritz E, Waldherr R: Dendritic cells in glomerulonephritis. Virchows Arch B Cell Pathol Incl Mol Pathol 1992;62:357-363. 
-28 Heymann F, Meyer-Schwesinger C, Hamilton-Williams EE, Hammerich L, Panzer U, Kaden S, Quaggin SE, Floege J, Grone HJ, Kurts C: Kidney dendritic cell activation is required for progression of renal disease in a mouse model of glomerular injury. J Clin Invest 2009;119:1286-1297.

-29 Segerer S, Hughes E, Hudkins KL, Mack M, Goodpaster T, Alpers CE: Expression of the fractalkine receptor (CX3CR1) in human kidney diseases. Kidney Int 2002;62:488495.

>30 Fiore N, Castellano G, Blasi A, Capobianco C, Loverre A, Montinaro V, Netti S, Torres D, Manno C, Grandaliano G, Ranieri E, Schena FP, Gesualdo L: Immature myeloid and plasmacytoid dendritic cells infiltrate renal tubulointerstitium in patients with lupus nephritis. Mol Immunol 2008;45:259-265.
31 De Palma G, Castellano G, Del Prete A, Sozzani S, Fiore N, Loverre A, Parmentier M, Gesualdo L, Grandaliano G, Schena FP: The possible role of CHEMR23/Chemerin axis in the recruitment of dendritic cells in lupus nephritis. Kidney Int 2011;79:1228-1235.

\$2 Tucci M, Quatraro C, Lombardi L, Pellegrino C, Dammacco F, Silvestris F: Glomerular accumulation of plasmacytoid dendritic cells in active lupus nephritis: role of interleukin-18. Arthritis Rheum 2008;58:251262.

33 Steinmetz OM, Velden J, Kneissler U, Marx M, Klein A, Helmchen U, Stahl RA, Panzer $\mathrm{U}$ : Analysis and classification of B-cell infiltrates in lupus and ANCA-associated nephritis. Kidney Int 2008;74:448-457.
34 Kruger T, Benke D, Eitner F, Lang A, Wirtz M, Hamilton-Williams EE, Engel D, Giese B, Muller-Newen G, Floege J, Kurts C: Identification and functional characterization of dendritic cells in the healthy murine kidney and in experimental glomerulonephritis. J Am Soc Nephrol 2004;15:613-621.

35 Figel AM, Brech D, Prinz PU, Lettenmeyer UK, Eckl J, Turqueti-Neves A, Mysliwietz J, Anz D, Rieth N, Muenchmeier N, Buchner A, Porubsky S, Siegert SI, Segerer S, Nelson PJ, Noessner E: Human renal cell carcinoma induces a dendritic cell subset that uses T-cell crosstalk for tumor-permissive milieu alterations. Am J Pathol 2011;179:436-451.

36 Segerer S, Schlondorff D: B cells and tertiary lymphoid organs in renal inflammation. Kidney Int 2008;73:533-537. 